\title{
A Proposed Strategy for Power Management of a Standalone Wind Energy Conversion System with Storage Battery
}

\author{
Toufik Laddi* Nabil Taib², Djamal Aouzellag $^{1}$ \\ ${ }^{1}$ Laboratoire de Maitrise des Energies Renouvelables (LMER), Faculté de Technologie, Université de Bejaia, 06000 Bejaia, Algeria \\ ${ }^{2}$ Laboratoire de technologie industrielle et de l'information (LTII), Faculté de Technologie, Université de Bejaia, 06000 Bejaia, Algeria \\ * Corresponding author, e-mail: ladditoufik@yahoo.fr
}

Received: 11 October 2019, Accepted: 09 January 2020, Published online: 20 May 2020

\begin{abstract}
Several strategies have been suggested to optimize power extracted from the Standalone Variable Speed Wind Energy Conversion System (SVSWECS) using a Squirrel Cage Induction Generator (SCIG). Where, many of them use the battery as a storage unit for future use. However, the latter is assumed as an ideal component and that no maximum charging or critical limit. With the considered strategy, the generated wind power can be managed using a fast and reliable fully rugged electrical control. Indeed, the use of reliable Power Management and Control (PMC) algorithm where the battery current is well controlled. However, this solution allows maintaining the system operation in two stable modes.

The considered system consists of an SCIG connected mechanically to the wind turbine through a gearbox, and electrically through a PWM rectifier to the DC bus capacitor, the latter is connected to the load and the battery through a PWM inverter and buck-boost converter respectively. In this paper, to approach the system to reality, a new PMC is proposed using a purely reliable electrical control. The Direct Torque Control (DTC) is used. The latter is combined with the Maximum Power Point Tracking (MPPT) technique and the State Of Charge (SOC) of battery. The important key of the proposed control strategy are the SOC and the sign of the difference between the generated and the demanded powers. The obtained simulations results are assessed and carried out using MATLAB/ Simulink package and show the effectiveness and the performance of the proposed algorithm.
\end{abstract}

\section{Keywords}

Squirrel Cage Induction Generator (SCIG), standalone, PWM converters, DTC control, variable speed, wind turbine, battery, Power Management and Control (PMC)

\section{Introduction}

Electricity generation plants have become a daily environmental issue, as they present a source of pollution. As a result, resources that use green energy have a very strong growth. Among renewable energies, wind energy is one of the most used for the production of electrical energy [1-4].

The use of Squirrel Cage Induction Generator (SCIG), Permanent Magnet Synchronous Generators (PMSG) and Doubly-Fed Induction Generators (DFIG) is recently preferred in the Wind Energy Conversion System (WECS) units. However, the PMSG suffers from high cost of materials and manufacturing [5-7] and the DFIG require an important maintenance costs mostly for offshore projects located in a saline medium [8-10].

Therefore, the SCIG has many advantages over other generators, such as robustness, low installation and maintenance costs which making it an ideal candidate to be used in the WECS [11-15].

In the Variable Speed Wind Energy Conversion Systems (VSWECS), the use of Maximum Power Point Tracking (MPPT) algorithm has a great importance, to extract the maximum power available in the wind [16-18]. So far, the MPPT algorithms researched can be classified into three main control methods, namely Power Signal Feedback (PSF) control, Hill-Climb Search (HCS) control and Tip Speed Ratio (TSR) control which is used in this paper. This technique is used to regulate the generator speed, in order to maintain the TSR to an optimum value at which power extracted is maximum [18].

In the VSWECS grid connection mode, all power extracted using the MPPT algorithm will be injected into 
the grid [19]. Nevertheless, in the Stand-alone Variable Speed Wind Energy Conversion System (SVSWECS) mode, the MPPT is used to meet the load requirements and the excess power will be stored in a storage unit for future use [20-23]. In this context, several works carried out in stand-alone VSWECS using the MPPT algorithm and storage unit (batteries).

However, to approach the system to the reality, the batteries have a maximum State Of Charge (SOC) which must not exceed. Beyond this, the life of the batteries is reduced, which leads to their deterioration.

Unfortunately, this assumption is not taken into account in all the works carried out for the stand alone WECS using the MPPT and batteries as storage unit. Therefore, in this paper, a new Power Management and Control (PMC) algorithm is proposed to ensure a reliable satisfaction of the load requirement and to protect the batteries as follow.

At the beginning, The SVSWECS operates using the MPPT mode to supply the load and to charge the batteries, when batteries are fully charged, to protect them, the PMC will disconnect them immediately, in this moment, the power generated becomes greater than that demanded by the load. So, this power difference can be dangerous to power converters.

Therefore, to rebalance the generated and consumed power, the PMC will deactivate the MPPT mode and activates the FREE mode.

For the FREE mode, the wind turbine will release to generate a wind torque following the generator electromagnetic torque, which has its turn following the load power. So, each variation in the load power will cause an imbalance in DC bus level which gives a novel electromagnetic torque value. To rebalance the system, the wind turbine will increase or decrease its rotational speed to find a new operating point. So that, the SVSWECS will only generates the power to supply the load.
The main important inputs of the proposed power management are the SOC of the batteries and the difference between the provided and demanded powers. The studied system is modeled and tested using the MATLAB/ Simulink package. The control of global system and the proposed power management are done for different operating conditions, such as sudden load variation and randomly fluctuations of the wind speed at the same time to approach the system to the reality.

\section{The studied system}

The global system studied in this paper consists of a wind turbine, SCIG, a PWM rectifier, a PWM inverter, a buckBoost converter and battery. In the SVSWECS, the regulation of the DC bus voltage is ensured by Generator Side Converter (GSC), and the regulation of the load three phase voltage and frequency is ensured by the Load Side Converter (LSC) as a secondary regulation of the load voltage.

Because the wind and the load are variable, a storage system is added at the dc voltage level through a buckboost converter to ensure the production/consumption balance. The proposed PMC is used to ensure the charging and discharging of the batteries, the connection and disconnection them (full charging or critical discharging level), and determines the operating mode of the wind turbine with or without MPPT. The system studied is then simplified as shown in Fig. 1.

\subsection{Turbine modeling}

The wind turbine converts part of the kinetic energy of the wind into a useful mechanical energy. The power extracted from the wind can be expressed in Eq. (1) as follows:

$P_{m}=\frac{1}{2} \pi \rho C p(\lambda) R^{2} v^{3}$,

where $\rho$ is the air density, $C p$ is the power coefficient, which is a function of $\lambda$ the TSR, $R$ is the radius of

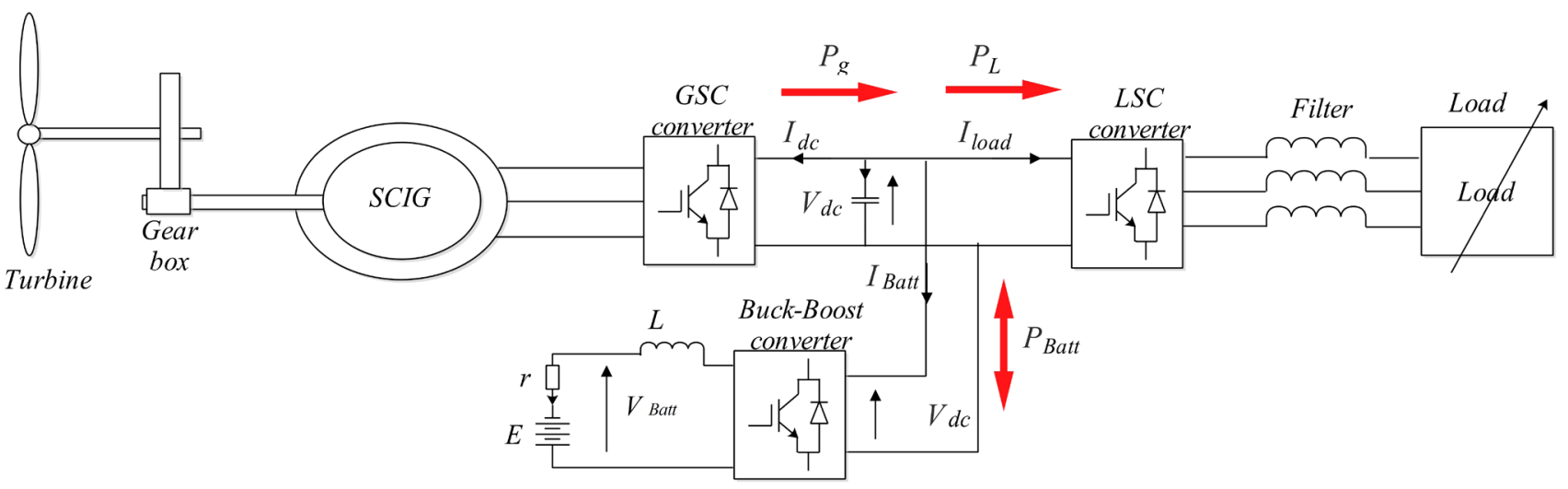

Fig. 1 Schematic diagram of the system studied 
the turbine and $v$ is the wind speed. The TSR and the power coefficient are given respectively by Eq. (2) and Eq. (3) respectively as follows:

$\lambda=\frac{\Omega_{t} R}{v}$

$C p(\lambda)=0.4 \sin \left(\pi \frac{\lambda+0.1}{12.8}\right)$,

where $\Omega_{t}$ is the angular speed of turbine, neglecting the friction forces, the dynamic equation of the wind turbine is given by:

$\frac{d \Omega_{r}}{d t}=\frac{1}{J}\left(T_{g}-T_{e m}\right)$,

where $\Omega_{r}$ is the angular speed of the generator, $J$ is the moment of inertia of the generator and the turbine, $T_{a}$ is the torque developed by the wind turbine brought back to the generator side and $T_{e m}$ is the generator electromagnetic torque.

The functional diagram of the turbine model is established in Fig 2. It shows that the turbine speed is controlled by action on the electromagnetic torque. The latter depends on the operating mode (FREE or MPPT mode). In the MPPT mode operation, the electromagnetic torque depends on the optimum parameters of the turbine $\lambda_{\text {opt }}$ and $C p_{\max }$, as the wind speed is randomly variable and considered as a disturbing input, the generator speed must be adjusted continuously to that of the wind for ensure maximum collection of wind energy. the battery current is positive during the charging mode and negative during the discharging mode, as it is known that the batteries can be charged more than $100 \%$, but they heat up and degrade over time, to protect it, the $\mathrm{SOC}_{\max }$ is set at $90 \%$, beyond this value the batteries must be disconnected, so its current is equal to zero. However, in the FREE mode operation, the electromagnetic torque is depend on the generator stator currents and flux, the latter is kept constant at the rated value using the Direct Torque Control (DTC) and the stator currents depend on the load currents via the DC bus capacitor, so any increasing of the load current will increase the call of the stator currents and increases the generator electromagnetic torque. In this case, the operating point will move to rebalance the dynamic equation of the turbine.

In this paper, the choice of operating mode of the turbine (FREE or MPPT mode) is decided by the proposed PMC algorithm taken into account the battery SOC and the difference power between the generator and the load.

\subsection{Battery modeling}

The battery is connected to the DC bus through a buckboost converter as shown in Fig. 1. The equivalent circuit of the battery is depicted in Fig. 3 .

The mathematical model of the battery voltages is written in Eqs. (5) and (6).

The SOC of the battery is the fraction of the current capacity of the battery at each time instant, divided by its nominal capacity; it is written in the Eq. (7):

$$
\begin{aligned}
& V_{\text {batt }}=E+R I_{\text {Batt }} \\
& E=E_{0}-K \frac{Q}{Q-I_{\text {Batt }} \cdot t}+A e^{\left(-B \cdot I_{\text {Bat }}\right)}
\end{aligned}
$$

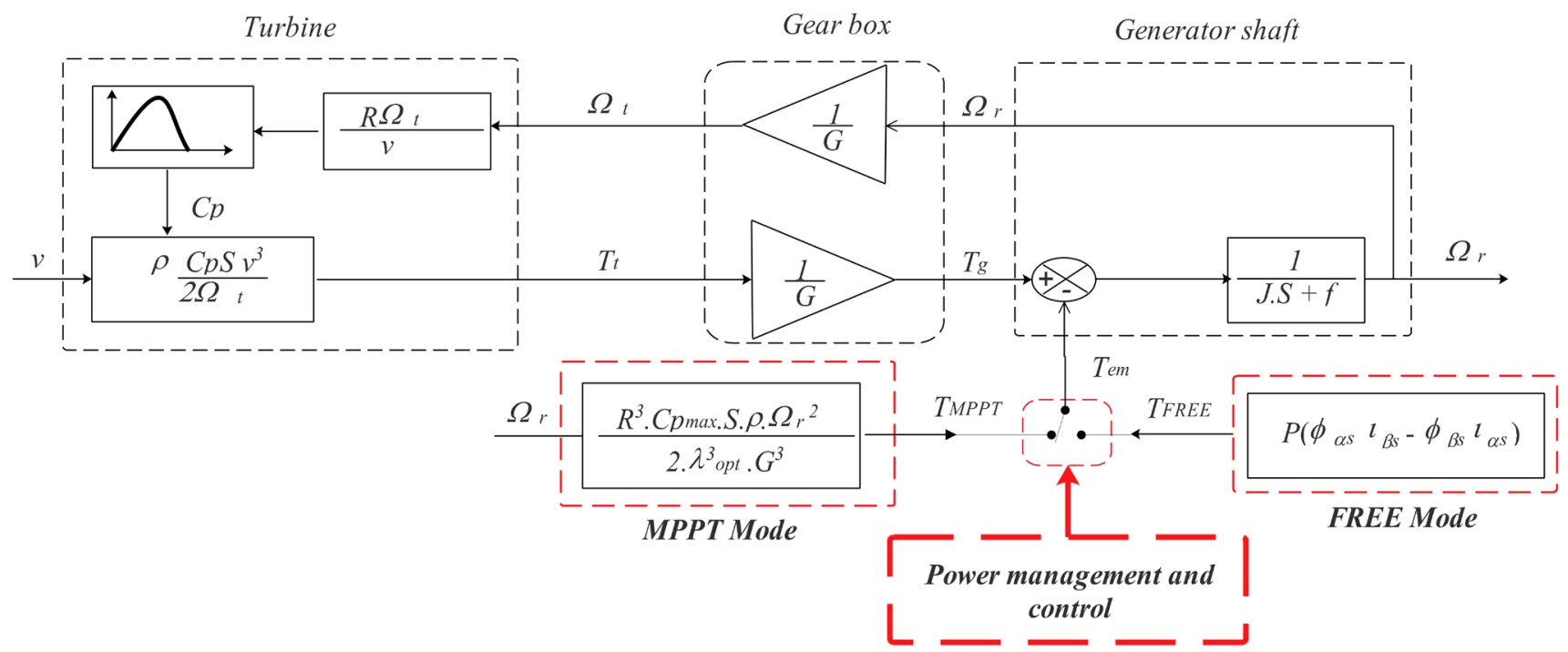

Fig. 2 The functional block diagram of the turbine model 


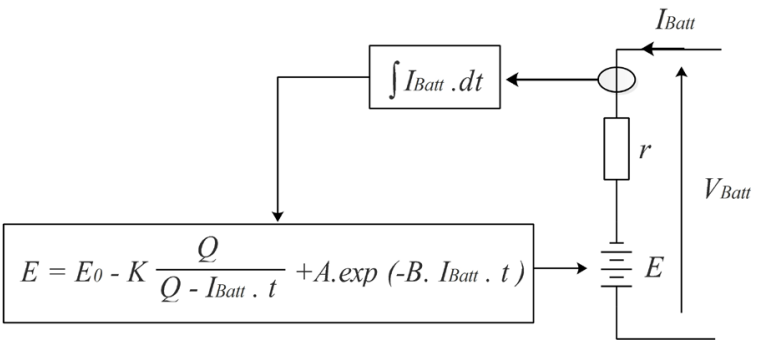

Fig. 3 The equivalent circuit of the battery

$\mathrm{SOC}=100 \cdot\left(\frac{\int_{0}^{t} I_{\text {Batt }} d t}{Q}\right)$,

where $E$ is the nonlinear voltage $(\mathrm{V}), E_{0}$ is the battery constant voltage $(\mathrm{V}), K$ is the polarization voltage $(\mathrm{V})$, $Q$ is the battery capacity (Ah), $A$ is the exponential zone amplitude (V), $B$ is the exponential zone time constant inverse $(\mathrm{Ah})^{-1}, V_{\text {batt }}$ is the battery voltage $(\mathrm{V}), r$ is the internal resistance and $I_{\text {Batt }}$ is the battery current (A).

\subsection{Generator modeling}

The mathematical model of the generator is the basis of the control implementation. The true modeling of SCIG leads to a precision and reliability of the applied control strategy. The generator is modeled in $\alpha-\beta$ using the Concordia transformation.

The $\alpha-\beta$ model of the SCIG provides a powerful physical interpretation of the interactions of currents and flux of such fate to produce voltages and torques, more importantly it leads to an easy adaptation with the proposed control strategies.

Under certain usual assumptions, the SCIG model can be written in the stator reference frame $\alpha-\beta[18,24]$ as follows (Eq. (8)):

$$
\left\{\begin{array}{l}
\frac{d}{d t} i_{\alpha s}=\frac{1}{\sigma L_{s}}\left[-R_{s r} i_{\alpha s}+\frac{M R_{r}}{L_{r}^{2}} \varphi_{\alpha r}+\frac{M}{L_{r}} \omega_{r} \varphi_{\beta r}+v_{d s}\right] \\
\frac{d}{d t} i_{\beta s}=\frac{1}{\sigma L_{s}}\left[-R_{s r} i_{\beta s}+\frac{M R_{r}}{L_{r}^{2}} \varphi_{\beta r}-\frac{M}{L_{r}} \omega_{r} \varphi_{\alpha r}+v_{q s}\right] \\
\frac{d}{d t} \varphi_{\alpha r}=\frac{M R_{r}}{L_{r}} i_{\alpha s}-\frac{R_{r}}{L_{r}} \varphi_{\alpha r}-\omega_{r} \varphi_{\beta r} \\
\frac{d}{d t} \varphi_{\beta r}=\frac{M R_{r}}{L_{r}} i_{\beta s}-\frac{R_{r}}{L_{r}} \varphi_{\beta r}+\omega_{r} \varphi_{\alpha r}
\end{array}\right.
$$

with

$$
R_{s r}=\left(R_{s}+R_{r} \frac{M^{2}}{L_{r}^{2}}\right) ; \sigma=\left(1-\frac{M^{2}}{L_{s} L_{r}}\right) ;
$$

where $R_{s}$ and $R_{r}$ are the stator and rotor resistances, $L_{s}$ and $L_{r}$ are the stator and rotor cyclical inductances respectively, $M$ is the mutual cyclical inductance, $\Omega_{r}$ is the mechanical speed of the machine which is measured continuously, the rotor pulsations is expressed by Eq. (10):

$\omega_{r}=P \Omega_{r}$.

\section{Generator control methodology}

The objective of the proposed control is to control the DC bus voltage from its desired value. It is possible to express the reference power by Eq. (11):

$P_{d c}^{*}=V_{d c}^{*} I_{d c}$,

where $I_{d c}$ is the output current of the generator side converter. By neglecting the generator losses, we obtain the reference electromagnetic torque expression in Eq. (12):

$T_{e m}^{*}=\frac{P_{d c}^{*}}{\Omega_{r}}$.

The control of $V_{d c}$ voltage can be carried out through the electromagnetic torque. In the present work, the DTC control is used. This control technique allows obtaining a fast and precise torque dynamics. The principle of this control is to directly control the torque and the stator flux of the SCIG. In this context, two hysteresis comparators are used which allow compare the estimated stator flux and electromagnetic torque with those of references, then we directly order the PWM converter states through a predefined commutation table (Table 1).

The amplitude of the stator flux is estimated from its components along the axes $\alpha$ and $\beta$ [24].

$\left\{\begin{array}{l}d \frac{\phi_{\alpha s}}{d t}=V_{\alpha s}+R_{s} i_{\alpha s} \\ d \frac{\phi_{\beta s}}{d t}=V_{\beta s}+R_{s} i_{\beta s}\end{array}\right.$

$\phi_{s}=\sqrt{\phi_{\alpha s}{ }^{2}+\phi_{\beta s}^{2}}$.

The electromagnetic torque is then obtained by Eq. (15):

$T_{e m}=P\left(\phi_{\alpha s} i_{\beta s}-\phi_{\beta s} i_{\alpha s}\right)$.

Table 1 The commutation table

\begin{tabular}{llllllll}
\hline$N$ & & 1 & 2 & 3 & 4 & 5 & 6 \\
\hline \multirow{4}{*}{$C_{f x}=1$} & $C_{c p l}=1$ & $V_{2}$ & $V_{3}$ & $V_{4}$ & $V_{5}$ & $V_{6}$ & $V_{1}$ \\
& $C_{c p l}=0$ & $V_{7}$ & $V_{0}$ & $V_{7}$ & $V_{0}$ & $V_{7}$ & $V_{0}$ \\
& $C_{c p l}=-1$ & $V_{6}$ & $V_{1}$ & $V_{2}$ & $V_{3}$ & $V_{4}$ & $V_{5}$ \\
\hline \multirow{4}{*}{$C_{f x x}=0$} & $C_{c p l}=1$ & $V_{3}$ & $V_{4}$ & $V_{5}$ & $V_{6}$ & $V_{1}$ & $V_{2}$ \\
& $C_{c p l}=0$ & $V_{0}$ & $V_{7}$ & $V_{0}$ & $V_{7}$ & $V_{0}$ & $V_{7}$ \\
& $C_{c p l}=-1$ & $V_{5}$ & $V_{6}$ & $V_{1}$ & $V_{2}$ & $V_{3}$ & $V_{4}$ \\
\hline
\end{tabular}

where $V_{0}=[000] ; V_{1}=[100] ; V_{2}=[110] ; V_{3}=[010] ; V_{4}=[011] ; V_{5}=[001]$; $V_{6}=[101] ; V_{7}=[111]$ 
The vectors $V_{0}$ and $V_{7}$ are chosen alternately so as to minimize the number of switching.

The purpose of the flux corrector is to keep the vector in a circular band around the reference value. The torque corrector performs the same function for the latter.

The commutation table (Table 1) is constructed as a function of the state of the variables of the flux corrector $C_{f x}$ and of the torque corrector $C_{c p l}$ and of the area $N$ of the position of $\phi_{s}$.

The Fig. 4 resumes the global system control and the relationship between different parts.

\section{The proposed PMC description}

The studied system using the proposed power management strategy has the advantage of being able to operate in two operating modes, the operation with or without the MPPT technique, the Fig. 5 explains and illustrates the dynamic behavior of the studied system in both operating zones as following.

Zone I: In this zone, the system operates with the MPPT mode, when the power generated by the SVSWECS is sufficient to satisfy the needs of the load, so the power difference is positive, this difference is invested to charge the batteries as long as they are not fully charged ( $\mathrm{SOC}<\mathrm{SOC}_{\max }$ ), or in the case where the power difference is negative i.e. the power demand by the load is greater than that generated, this power difference will be compiled by the stored power in the batteries as long as they are not completely discharged ( $\mathrm{SOC}>\mathrm{SOC}_{\min }$ ). In this case, the $C p$ and $\lambda$ are maintained at the maximum and optimum values respectively, $C p=C p_{\max }$ and $\lambda=\lambda_{\text {opt }}$.

Zone II: In this zone, the system operates with the FREE mode, at the batteries disconnection time (fully charged), the produced power comes then greater than that demanded. So, the MPPT technique is disabled by the proposed PMC. Therefore, the wind turbine operates with a power coefficient and a tip speed ratio below and above the maximum and the optimum values respectively $C p<C p_{\max }$ and $\lambda>\lambda_{\text {opt }}$. At this moment the turbine speed increase to reduce the generated torque which makes a displacement of the operating point according to the load power.

The dynamics of charging and discharging of batteries is much faster, so it can effectively cover the fluctuations of wind energy due to the random nature of the wind, given the importance of batteries in the global system. The net power of the system is calculated as the difference between the generated and demanded powers as follows:

$$
P_{0}=P_{g}-P_{L}
$$

The Fig. 6 represents the proposed logical diagram.

\section{Simulation results}

The nominal parameters of the SCIG, the wind turbine and the battery are written in the appendix. The battery is assumed initially charged at $50 \%$. The value of the DC bus voltage reference is put equal to $650 \mathrm{~V}$, the reference

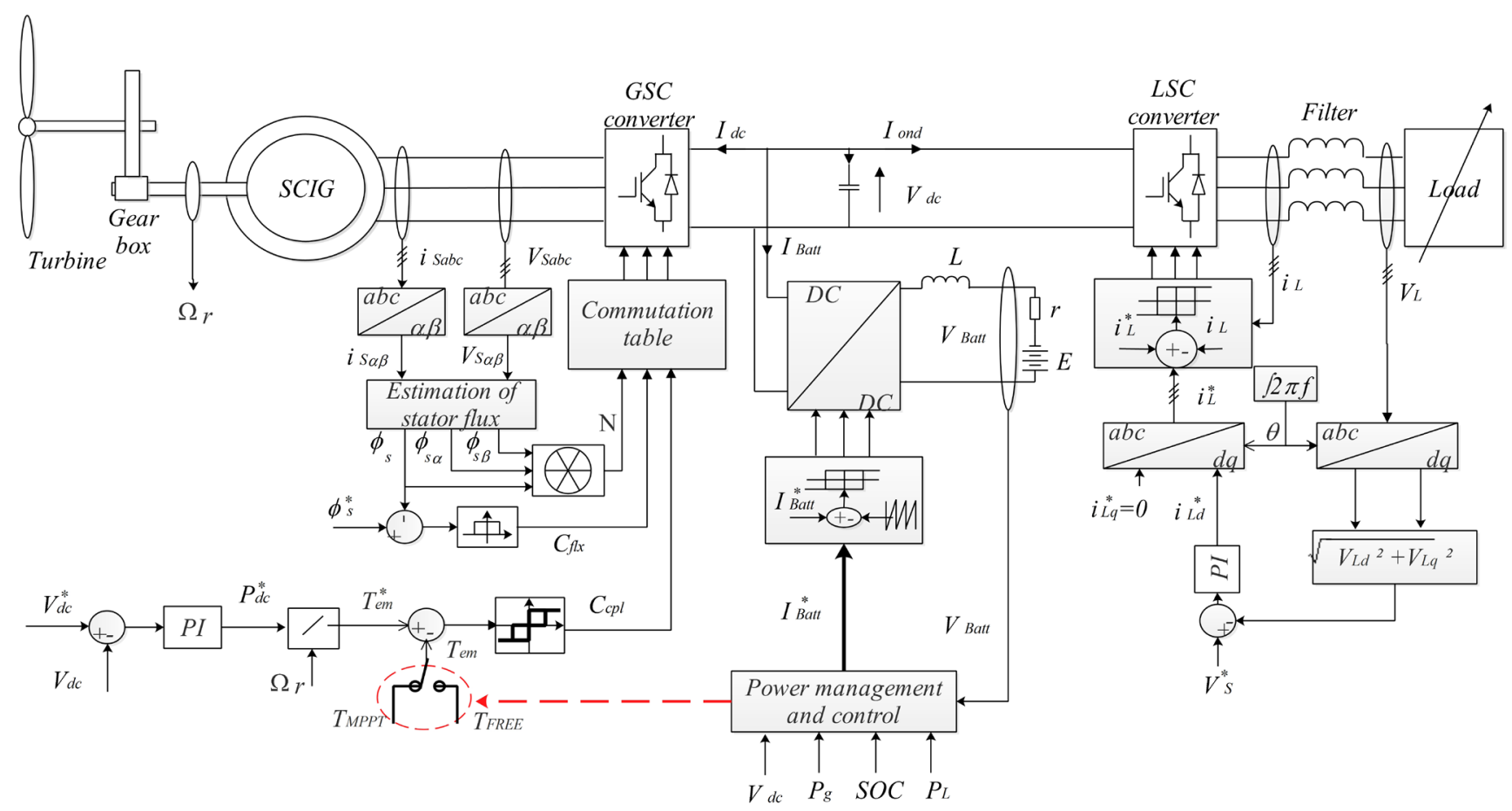

Fig. 4 The global system control 


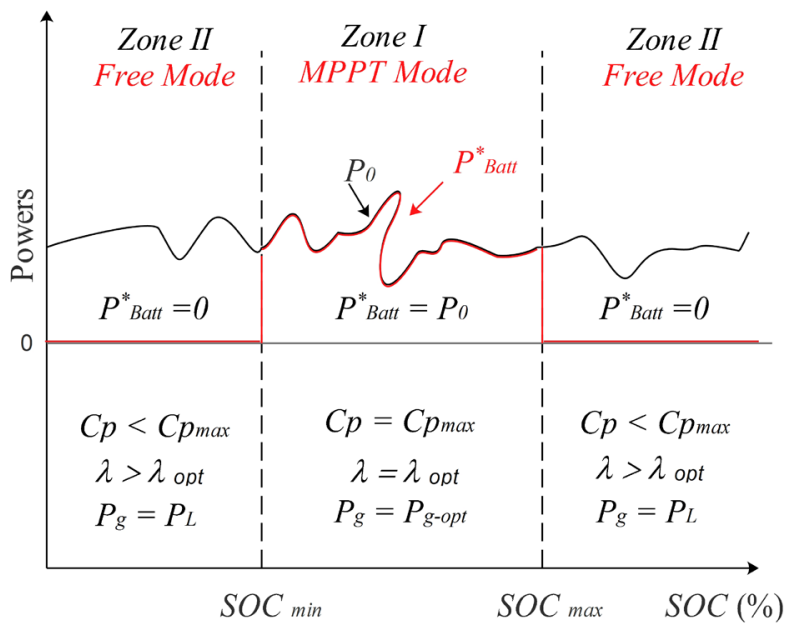

Fig. 5 Schematic explanation of operating modes

stator flux is set equal to its rated value $0.7 \mathrm{~Wb}$. The voltage of three phase LSC converter output is regulated at its reference value $V_{s}^{*}=220 \sqrt{3} / 50 \mathrm{~Hz}$. The load is assumed balanced and purely resistive which is initially taken equal to $3 \mathrm{~kW}$. At $t=2 \mathrm{~s}$, the batteries are inserted, at time $t=20 \mathrm{~s}$, the load power is increased to $4.5 \mathrm{~kW}$, then it reduced to its initial value at time $t=40 \mathrm{~s}$, the wind speed varies randomly around the nominal speed $(v=8 \mathrm{~m} / \mathrm{s})$ as shown in Fig. 7 .

For this test, the wind speed profile and the load sudden variations are intentionally chosen to highlight the advantage of the developed control strategy to swing between the both operating modes.
As shown in Fig. 8 and Fig. 9, the studied system can operate in two operating zones, with or without using of MPPT strategy. In the MPPT mode, the power coefficient is equal to 0.4 which the maximum value (Fig. 9) with an optimum rotation speed (Fig. 8). It is clearly seen in this operating mode that the generator speed varies proportionally with the load power variations. However, in the FREE mode, the generator speed varies over a wide speed range which can be almost twice the nominal speed (Fig. 8) with decrease in the power coefficient (Fig. 9). In this mode, the generator speed varies inversely proportional with the load power variations. So, the operating point varies and stabilizes according to the power demanded by the load.

Note that the speed variation is a slow process because it is determined by the inertia of system, in order to clearly see the variation of the $C p$ versus $\lambda$ a long test time, the 3D illustration is shown in Fig. 10.

It can be seen from Fig. 11 that the DC bus voltage is well regulated and is insensitive to the load variations. An overrun is not exceeded by $5 \%$ due to the disconnection of batteries which support the robustness of the DTC control.

The Fig. 12 shows that the stator flux is well controlled and it is insensitive to the variation of the load and the connection and disconnection of batteries. The stator currents are shown in Fig. 13, and the electromagnetic torque is shown in Fig. 14. It is well seen form these figures that

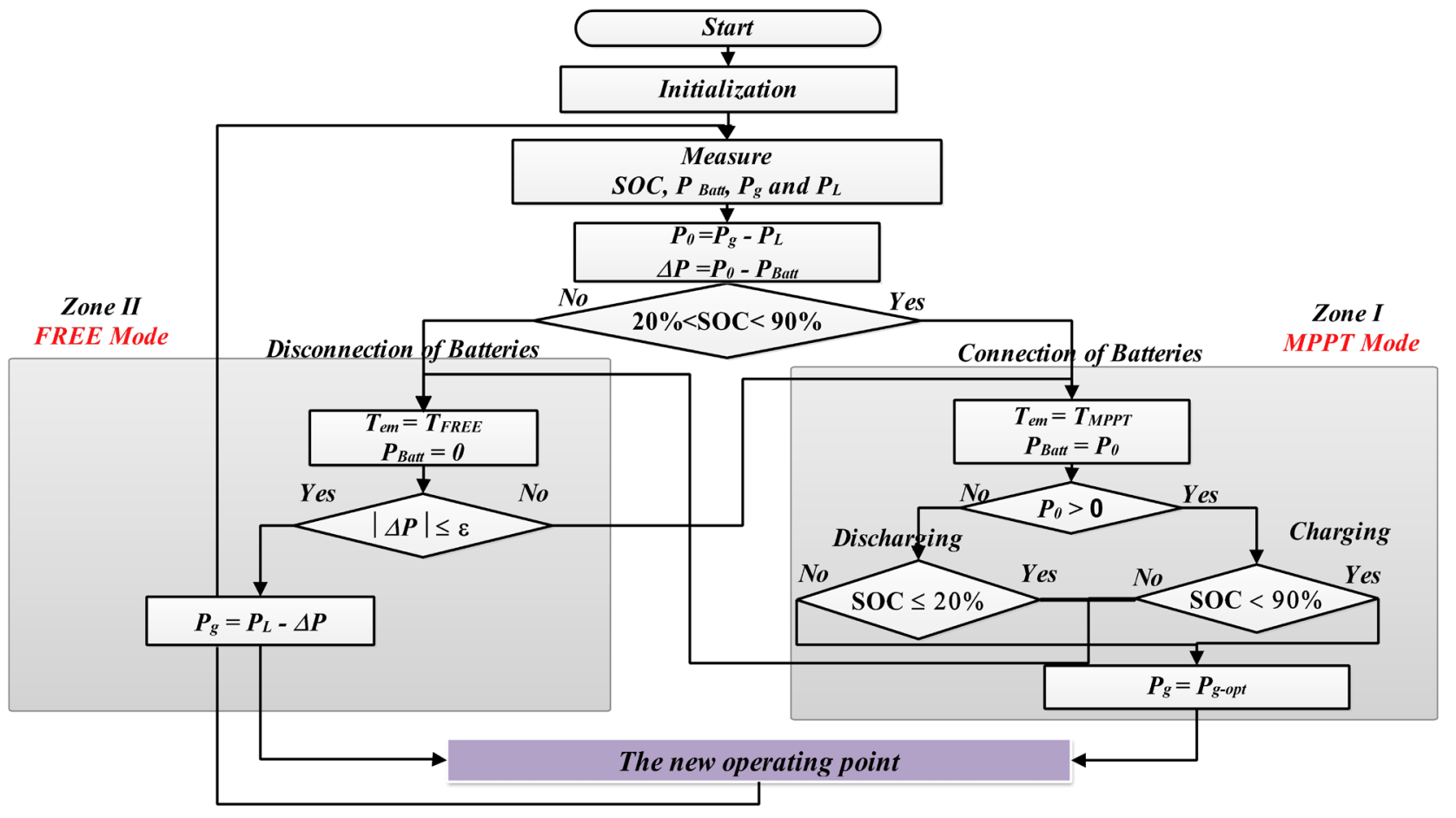

Fig. 6 Logical block diagram 


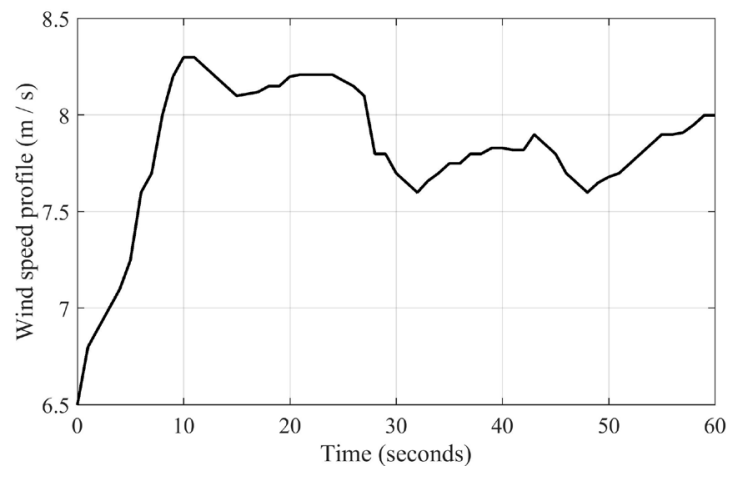

Fig. 7 Wind speed profile

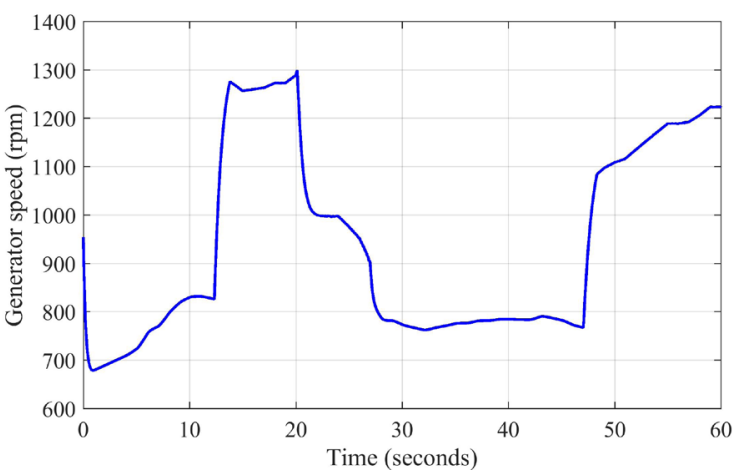

Fig. 8 Generator rotor speed (rpm)

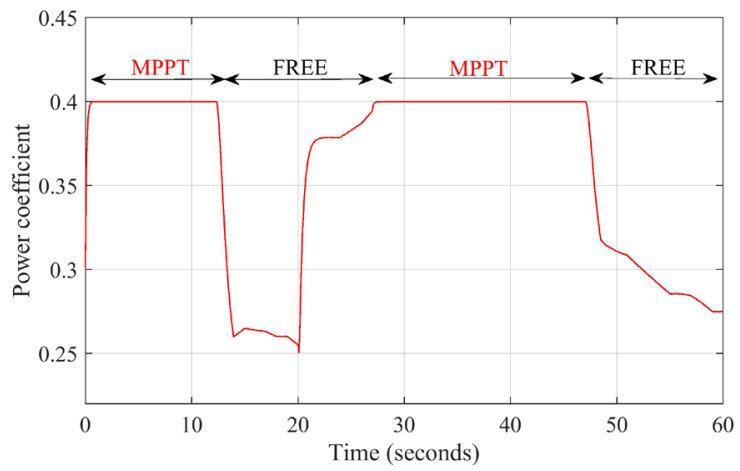

Fig. 9 Power coefficient

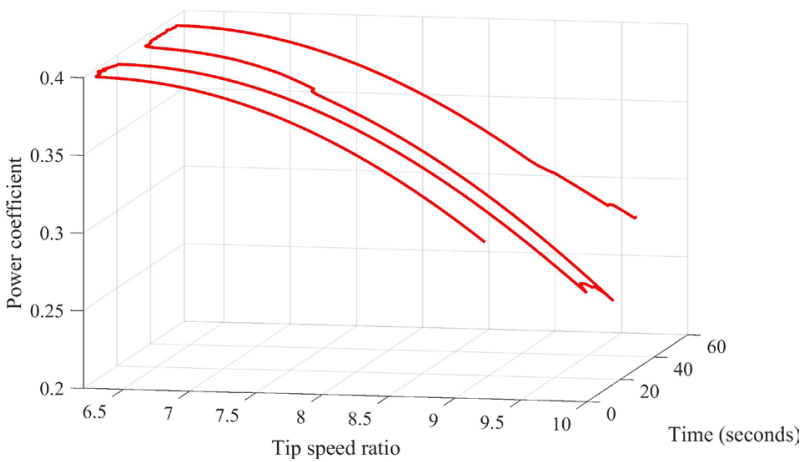

Fig. 10 The $C p$ versus $\lambda$ a long test time

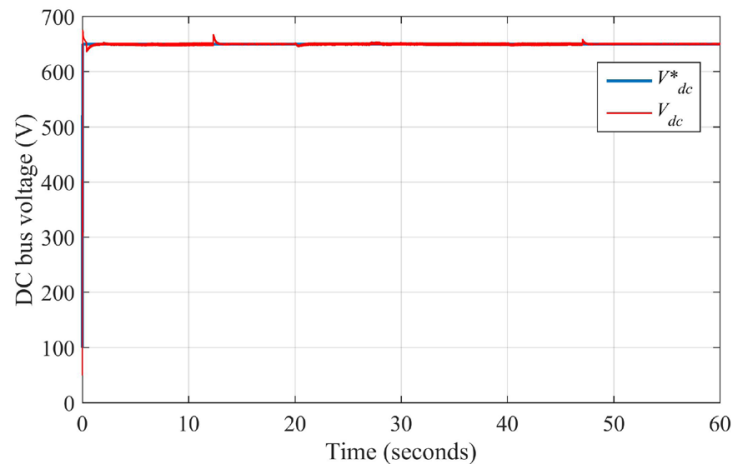

Fig. 11 DC bus voltage

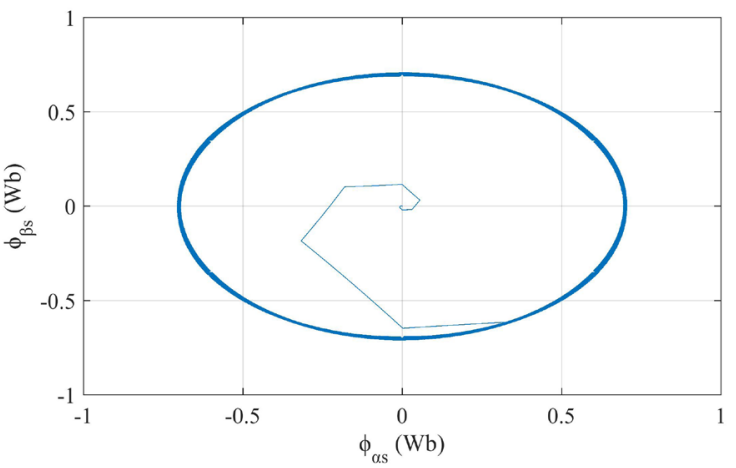

Fig. $12 \alpha-\beta$ axis stator flux

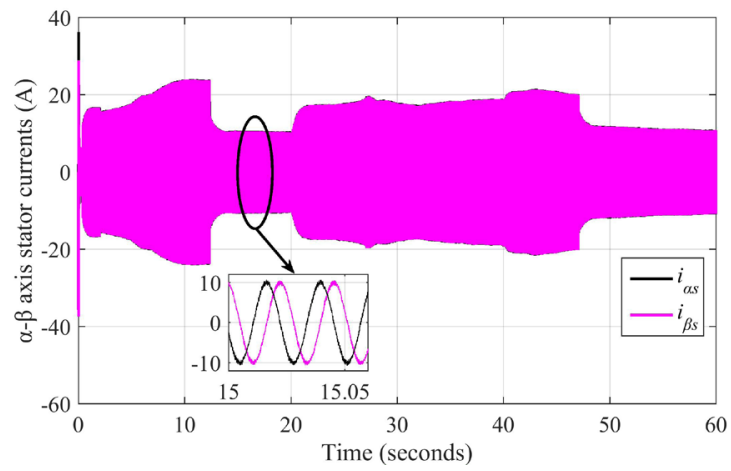

Fig. $13 \alpha-\beta$ axis stator currents

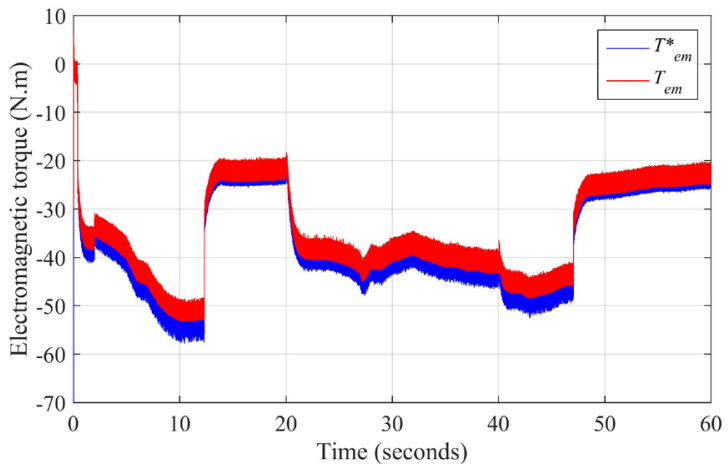

Fig. 14 Generator electromagnetic torque 
the stator currents and the electromagnetic torque are depend on the variation of the load power, the rotational speed of the rotor and the current of batteries.

The $\mathrm{SOC}_{\max }$ presents the key of choose the operating mode. In the FREE mode, the SOC is no change which translates the no charging or discharging of the batteries as show the Fig. 15.

The battery current is positive during the charging mode and negative during the discharging mode. In order to protect the batteries, the $\mathrm{SOC}_{\text {max }}$ is set at $90 \%$, beyond this value the batteries must be disconnected (FREE mode), so its current is equal to zero as shown in Fig. 16.

The different powers are represented in Fig. 17, we can see that the system generates an optimal power using MPPT mode, but at time $t=13 \mathrm{~s}$ where the batteries are disconnected, the system swing to operate in FREE mode to generate only the requested power. A transient regime has appeared, this is because of the mechanical response due to total inertia of the rotor shaft and turbine.

At time $t=27 \mathrm{~s}$, the power generated is insufficient to satisfy the needs of the load, this lack of power is compensated by the stored power in the batteries using the MPPT mode. It can be seen too that the proposed control strategy plays a very important role to protect

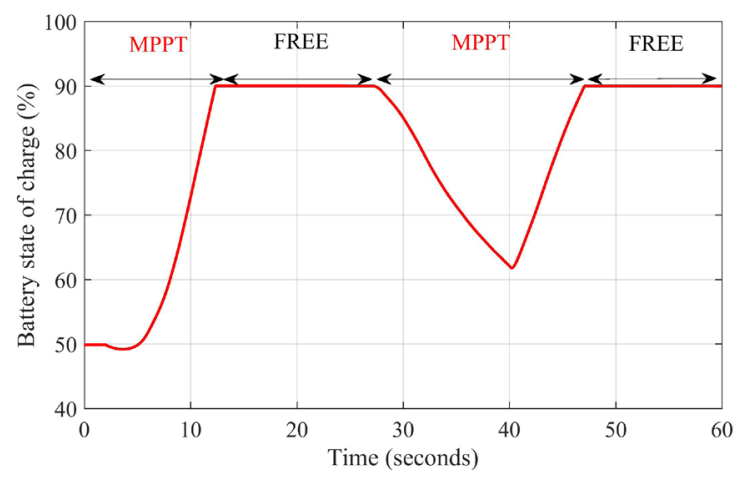

Fig. 15 State of charge of battery

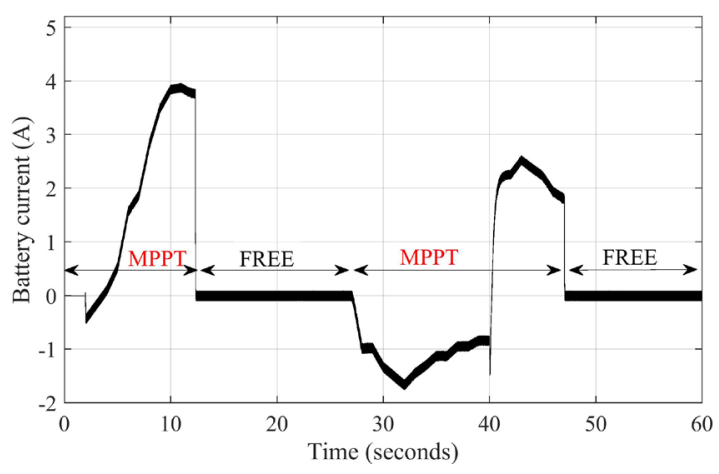

Fig. 16 Battery current variation curve

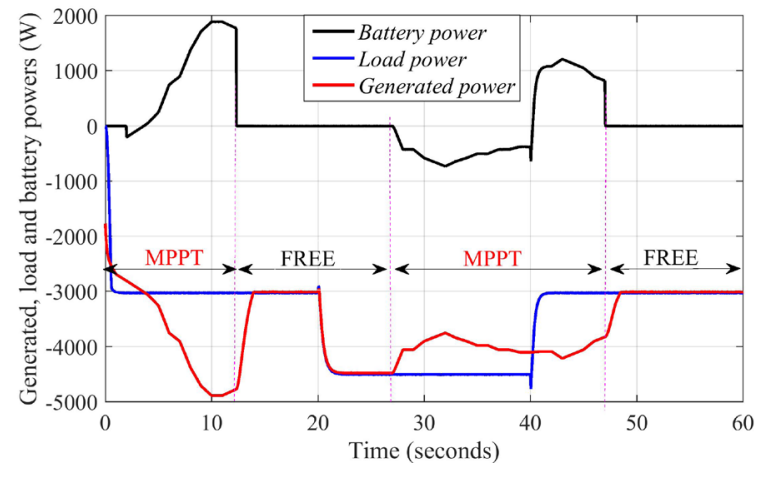

Fig. 17 Generator, load and battery powers

the global system and to supply the load sufficiently in acceptable operating conditions. The Fig. 18 shows the load current and voltage, it can be clearly seen that the load current depends just of the load variations. The load voltage is well controlled and established to its reference value. In order to obtain a constant load voltage value, a principally voltage control is done by regulating the DC bus voltage, and a secondary regulation is done through the LSC by imposing another voltage reference.

In addition, this technique allows to create a new level voltage which different to the DC bus voltage value. So, the load voltage is insensitive to the variation of the wind speed and disconnection of batteries, its frequency is fixed to $50 \mathrm{~Hz}$ whatever the variation speed of the turbine, we can to say the term, Variable Speed System and Constant Frequency (VSSCF).

\section{Conclusion}

In this paper, a real power management and control for the SVSWECS with storage battery based on SCIG was proposed, an analytical model of the SCIG in the $\alpha-\beta$ frame has been presented to extract the control laws using the DTC control, this strategy allows to maintain the DC bus voltage at a constant value however the speed

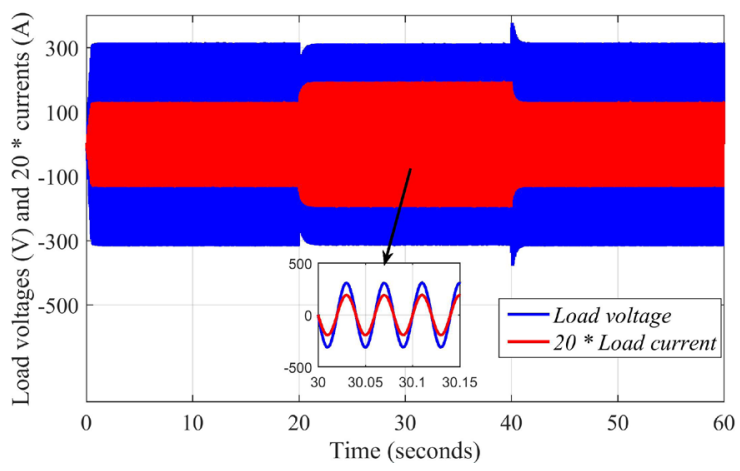

Fig. 18 Load voltage and $20 \times$ load currents curve 
of the wind and the sudden load variations. This control makes it possible to adjust the stator flux and the electromagnetic torque by generating a corresponding voltage vector to make them to follow theirs references.

In addition, to protect the storage batteries and the power converters, a PMC has been proposed to determine the use limits of the MPPT technique.

\section{References}

[1] Ouammi, A., Dagdougui, H., Sacile, R., Mimet, A. "Monthly and seasonal assessment of wind energy characteristics at four monitored locations in Liguria region (Italy)", Renewable Energy Reviews, 14(7), pp. 1959-1968, 2010.

https://doi.org/10.1016/j.rser.2010.04.015

[2] Warne, D. F., Calnan, P. G. "Generation of electricity from the wind", Proceedings of the Institution of Electrical Engineers, 124(11R), pp. 963-985, 1977. https://doi.org/10.1049/piee.1977.0229

[3] Infield, D., Freris, L., Murray, B. "Renewable Energy in Power Systems", John Wiley and Sons, Chichester, U.K., 2008.

[4] Tang, Y., Xu, L. "A flexible active and reactive power control strategy for a variable speed constant frequency generating system", IEEE Transactions on Power Electronics, 10(4), pp. 472-478, 1995. https://doi.org/10.1109/63.391945

[5] Aissou, R., Rekioua, T., Rekioua, D., Tounzi, A. "Robust Nonlinear Predictive Control of Permanent Magnet Synchronous Generator Turbine Using Dspace Hardware", International Journal of Hydrogen Energy, 41(45), pp. 21047-21056, 2016. https://doi.org/10.1016/j.ijhydene.2016.06.109

[6] Sahu, A., Gupta, S., Singh, V. K., Bhoi, A. K., Garg, A., Sherpa, K. S. "Design of Permanent Magnet Synchronous Generator for Wind Energy Conversion System", In: Gupta, S., Zobaa, A., Sherpa, K., Bhoi, A. (eds.) Advances in Smart Grid and Renewable Energy, Lecture Notes in Electrical Engineering, Springer, Singapore, Singapore, 435, pp. 23-32, 2018.

https://doi.org/10.1007/978-981-10-4286-7_3

[7] Zhou, D., Blaabjerg, F., Franke, T., Tonnes, M., Lau, M. "Comparison of Wind Power Converter Reliability With LowSpeed and Medium-Speed Permanent-Magnet Synchronous Generators", IEEE Transactions on Industrial Electronics, 62(10), pp. 6575-6584, 2015.

https://doi.org/10.1109/TIE.2015.2447502

[8] Taraft, S., Rekioua, D., Aouzellag, D., Bacha, S. "A Proposed Strategy for Power Optimization of a Wind Energy Conversion System Connected to the Grid", Energy Conversion and Management, 101, pp. 489-502, 2015.

https://doi.org/10.1016/j.enconman.2015.05.047

[9] Abdoune, F., Aouzellag, D., Ghedamsi, K. "Terminal Voltage Build-up and Control of a DFIG Based Stand-alone Wind Energy Conversion System", Renewable Energy, 97, pp. 468-480, 2016. https://doi.org/10.1016/j.renene.2016.06.005
The simulation results show that the proposed control system adds high performance dynamic and flexibility to the SVSWECS to make the system very robust with respect to wind speed and load variations.

[10] Hu, J., Nian, H., Hu, B., He, Y., Zhu, Z. Q. "Direct Active and Reactive Power Regulation of DFIG Using Sliding-Mode Control Approach", IEEE Transaction on Energy Conversion, 25(4), pp. 1028-1039, 2010. https://doi.org/10.1109/TEC.2010.2048754

[11] Carunaiselvane, C., Chelliah, T. R. "Present Trends and Future Prospects of Asynchronous Machines in Renewable Energy Systems", Renewable and Sustainable Energy Reviews, 74, pp. 1028-1041, 2017. https://doi.org/10.1016/j.rser.2016.11.069

[12] Ahmed, T., Noro, O., Hiraki, E., Nakaoka, M. "Terminal Voltage Regulation Characteristics by Static Var Compensator for a ThreePhase Self-Excited Induction Generator", IEEE Transactions on Industry Applications, 40(4), pp. 978-988, 2004. https://doi.org/10.1109/TIA.2004.830783

[13] Chen, Z., Hu, Y., Blaabjerg, F. "Stability improvement of Induction Generator-Based Wind Turbine Systems", IET Renewable Power Generation, 1(1), pp. 81-93, 2007. https://doi.org/10.1049/iet-rpg:20060021

[14] Watson, D. B., Arrillaga, J., Densem, T. "Controllable dc Power Supply From Wind Driven Self-excited Induction Machines", Proceedings of the Institution of Electrical Engineers, 126(12), pp. $1245-1248,1979$. https://doi.org/10.1049/piee.1979.0216

[15] Deraz, S. A., Abdel Kader, F. E. "A New Control Strategy for a Stand-alone Self-excited Induction Generator Driven by a Variable Speed Wind Turbine", Renewable Energy, 51, pp. 263-273, 2013. https://doi.org/10.1016/j.renene.2012.09.010

[16] Koutroulis, E., Kalaitzakis, K. "Design of a Maximum Power Tracking System for Wind-Energy-Conversion Applications", IEEE Transactions on Industrial Electronics, 53(2), pp. 486-494, 2006. https://doi.org/10.1109/TIE.2006.870658

[17] Wang, Q., Chang, L. "An Intelligent Maximum Power Extraction Algorithm for Inverter-Based Variable Speed Wind Turbine Systems", IEEE Transactions on Power Electronics, 19(5), pp. 1242-1249, 2004. https://doi.org/10.1109/tpel.2004.833459

[18] Novaes Menezes, E. J., Maurício Araújo, A., Bouchonneauda Silva, N.S. "A Review on Wind Turbine Control and its Associated Methods", Journal of Cleaner Production, 174, pp. 945-953, 2018. https://doi.org/10.1016/j.jclepro.2017.10.297 
[19] Nishida, K., Ahmed, T., Nakaoka, M. "A Cost-Effective HighEfficiency Power Conditioner With Simple MPPT Control Algorithm for Wind-Power Grid Integration", IEEE Transactions on Industry Applications, 47(2), pp. 893-900, 2010.

https://doi.org/10.1109/TIA.2010.2103294

[20] Marisarla, C., Kumar, K. R. "A Hybrid Wind and Solar Energy System with Battery Energy Storage for an Isolated System", International Journal of Engineering and Innovative Technology, 3(3), pp. 99-104, 2013.

[21] Martin, S. S., Chebak, A., Elouafi, A., Mabrouki, M. "Modeling and Simulation of Hybrid Power System Integrating Wind, Solar, Biodiesel Energies and Storage Battery", In: 2016 International Renewable and Sustainable Energy Conference (IRSEC), Marrakech, Marocco, 2016, pp. 457-463.

https://doi.org/10.1109/IRSEC.2016.7984017

\section{Appendix}

Parameters of the SCIG:

$P_{N}=5.5 \mathrm{~kW}, U_{N}=220 / 380 \mathrm{~V}, I_{N}=23.8 / 13.7 \mathrm{~A}, 50 \mathrm{~Hz}$,

$R_{s}=1.0713 \Omega, R_{r}=1.2951 \Omega, p=4, \Omega_{N}=690 \mathrm{rpm}$,

$J=0.230 \mathrm{~kg} \cdot \mathrm{m}^{2}, K_{f}=0.0025 \mathrm{~N} \cdot \mathrm{m} \cdot \mathrm{s}$.

Parameters of the turbine:

$G=31425, R=3.24 \mathrm{M}, \lambda_{\text {opt }}=6.3, C p_{\max }=0.4$.
[22] Barote, L., Weissbach, R., Teodorescu, R., Marinescu, C., Cirstea, M. "Stand-alone Wind System with Vanadium Redox Battery Energy Storage", In: 2008 11th International Conference on Optimization of Electrical and Electronic Equipment, Brasov, Romania, 2008, pp. 407-412.

https://doi.org/10.1109/optim.2008.4602441

[23] Masaud, T. M., Oyebanjo, O., Sen, P. K. "Sizing of Large-Scale Battery Storage for Off-Grid Wind Power Plant Considering a Flexible Wind Supply-Demand Balance", IET Renewable Power Generation, 11(13), pp. 1625-1632, 2017. https://doi.org/10.1049/iet-rpg.2016.0839

[24] Idjdarene, K. "Contributionà l'Étude et la Commande de Génératrices Asynchrones à Cage dédiées à des Centrales Électriques Éoliennes Autonomes" (Contribution to the Study and the Control of Asynchronous Cage Generators dedicated to Autonomous Wind Power Plants), Doctoral dissertation, Doctoral School of Engineering Sciences, University of Lille, 2010. (in French) 